\title{
Foot-and-mouth disease virus-like particles produced by a SUMO fusion protein system in Escherichia coli induce potent protective immune responses in guinea pigs, swine and cattle
}

Hui-Chen Guo ${ }^{1 \dagger}$, Shi-Qi Sun ${ }^{1 *+}$, Ye Jin ${ }^{1}$, Shun-Li Yang ${ }^{1}$, Yan-Quan Wei ${ }^{1}$, De-Hui Sun ${ }^{1}$, Shuang-Hui Yin ${ }^{1}$, Jun-Wu Ma', Zai-Xin Liu', Jian-Hong Guo ${ }^{1}$, Jian-Xun Luo ${ }^{1}$, Hong Yin ${ }^{1}$, Xiang-Tao Liư ${ }^{*}$ and Ding Xiang Liu ${ }^{1,2^{*}}$

\begin{abstract}
Foot-and-mouth disease virus (FMDV) causes a highly contagious infection in cloven-hoofed animals. The format of FMD virus-like particles (VLP) as a non-replicating particulate vaccine candidate is a promising alternative to conventional inactivated FMDV vaccines. In this study, we explored a prokaryotic system to express and assemble the FMD VLP and validated the potential of VLP as an FMDV vaccine candidate. VLP composed entirely of FMDV (Asia1/Jiangsu/China/2005) capsid proteins (VPO, VP1 and VP3) were simultaneously produced as SUMO fusion proteins by an improved SUMO fusion protein system in E. coli. Proteolytic removal of the SUMO moiety from the fusion proteins resulted in the assembly of VLP with size and shape resembling the authentic FMDV. Immunization of guinea pigs, swine and cattle with FMD VLP by intramuscular inoculation stimulated the FMDV-specific antibody response, neutralizing antibody response, T-cell proliferation response and secretion of cytokine IFN- $\gamma$. In addition, immunization with one dose of the VLP resulted in complete protection of these animals from homologous FMDV challenge. The $50 \%$ protection dose $\left(\mathrm{PD}_{50}\right)$ of FMD VLP in cattle is up to 6.34. These results suggest that FMD VLP expressed in E. coli are an effective vaccine in guinea pigs, swine and cattle and support further development of these VLP as a vaccine candidate for protection against FMDV.
\end{abstract}

\section{Introduction}

Foot-and-mouth disease (FMD) is an acute, highly contagious viral disease, which may cause severe economic losses in susceptible cloven-hoofed animals [1,2]. In 1997 an FMD outbreak was reported in Taiwan which had been free of the disease for 68 years. This devastating outbreak resulted in the slaughter of more than 4 million pigs, almost $38 \%$ of the entire pig population, at a cost of approximately U.S. $\$ 6$ billion [3]. In 2001 a

\footnotetext{
* Correspondence: shiqisun21@hotmail.com; hnxiangtao@hotmail.com; dxliu@ntu.edu.sg

${ }^{\dagger}$ Equal contributors

'State Key Laboratory of Veterinary Etiological Biology, National Foot and Mouth Disease Reference Laboratory, Lanzhou Veterinary Research Institute, Chinese Academy of Agricultural Sciences, Xujiaping 1, Lanzhou, Gansu 730046, China

${ }^{2}$ School of Biological Sciences, Nanyang Technological University, 60 Nanyang Drive, Nanyang 637551, Singapore

Full list of author information is available at the end of the article
}

large FMD outbreak started in the United Kingdom [4] and spread to France, Ireland and The Netherlands. The losses to agriculture in the United Kingdom alone were about $£ 3.1$ billion [5]. These outbreaks have significantly increased public awareness of this highly infectious disease and highlight the importance of disease control, including regular vaccination and slaughter of infected and contact animals, in endemic areas [6,7]. Although the conventional inactivated FMDV vaccine has been extremely successful in reducing the number of disease outbreaks in many parts of the world where the disease is enzootic, there are a number of concerns and limitations with its use in emergency control programs. Among these concerns and limitations, safety issues such as the possibility of virus escape during vaccine production and through insufficient chemical inactivation of virus highlight the need for the development of new generation vaccines.

\section{Biomed Central}


Recently, virus-like particles (VLP) are increasingly recognized as safe, effective vaccine candidates for viral diseases [8]. VLP are virus-sized particles with the supra-molecular structures that have the form of rods or icosahedrons [9]. They are composed of multiple copies of one or more recombinant expressed viral structural proteins which spontaneously assemble into particles without incorporation of the viral genome. They display antigens in an ordered and repetitive way, thus inducing rapid, robust humoral immune responses as well as efficient T-cell responses [10]. Because VLP combine many of the advantages of whole virus vaccines and recombinant subunit vaccines into one system, two VLP vaccines, including the papillomavirus vaccine and the hepatitis $B$ virus vaccine, are already licensed for use in humans, and a number of other VLP vaccines are being tested [8]. Many attempts have also been made to produce FMD VLP in a variety of hosts. The VLP-based FMD vaccines produced in baculovirus/insect cells, baculovirus/silkworm larvae, and by a replicationdeficient human adenovirus vector-based system are two of the successful recombinant vaccine candidates in protecting the target species (cattle or swine) against FMDV challenge [11-20]. The FMD VLP vaccine candidate produced by the deficient adenovirus is currently being manufactured in experimental batches and tested in cattle in the US mainland (for the first time in US history) as part of the veterinary licensing process [20]. Lee et al. reported the VLP produced in bacteria [21]. However, the immunogenicity of this VLP has not been evaluated. Compared with eukaryotic expression systems, such as insect and mammalian cells, expression of heterologous genes in bacteria is by far the simplest and most inexpensive means available for research or commercial purposes. However, only $>20 \%$ of heterologous genes expressed in $E$. coli render soluble or correctly folded proteins [22]. In order to improve the expression efficiency of heterologous proteins in E. coli, many modifications have been made, including the development of strong promoters [23], coexpression with chaperones [24] and use of protein fusions. Among them, expression of the recombinant proteins such as fusion proteins, especially for difficult-to-express proteins, is one of the most effective ways in improving the solubility of recombinant proteins. Several gene-fusion systems, such as NusA, maltose binding protein (MBP), glutathione-S -transferase (GST), ubiquitin (UB), and thioredoxin (Trx), have been developed $[25,26]$. These fusion proteins are frequently employed to enhance protein expression and to facilitate purification [27-29]. Recently, small ubiquitinlike modifier (SUMO) protein, a ubiquitin-related protein, has emerged as an effective biotechnological tool, since SUMO usually promotes correct folding and structural stability of the fusion proteins, leading to enhanced functional production of the partner proteins compared to its untagged version [30].

The FMDV genome is a positive-sense, single-stranded RNA with one large open reading frame. Its translation yields a polyprotein that is subsequently processed by virus-encoded proteases to produce structural and nonstructural proteins necessary for virus assembly and replication. One of the initial polyprotein cleavage events, mediated by the $2 \mathrm{~A}$ protein, is co-translational cleavage at the $\mathrm{N}$ terminus of the $2 \mathrm{~B}$ protein. The $\mathrm{P} 1-2 \mathrm{~A}$ precursor is processed by a viral $3 \mathrm{C}$ protease to produce the structural proteins VP0, VP1 and VP3. These proteins can then self-assemble to form icosahedral empty capsid particles [31-33], which consist of 60 copies of each protein. Many attempts have been made to produce FMDV capsid protein(s) and subsequently assemble into VLP in eukaryotic expression systems by combining the P1-2A and $3 \mathrm{C}$, in order to assemble virus capsids correctly $[12,34]$. However, this strategy has not been achieved in prokaryotic expression systems, especially in E. coli. To overcome this technical bottleneck, we recently developed an improved SUMO fusion protein system in E. coli according to previous research [21] and produced several water-soluble virus capsid proteins. Fusion proteins of three FMDV capsid proteins, VP0, VP1 and VP3, were efficiently expressed by the SUMO expression system in E. coli. After removal of the SUMO moiety from the fusion proteins, the three capsid proteins could be assembled into VLP with size and shape resembling the authentic FMDV. These VLP were prepared and used as an immunogen in guinea pigs, swine and cattle. The data show that FMDV-specific antibodies, neutralizing antibodies, T-cell proliferation and secretion of IFN- $\gamma$ were efficiently induced in the immunized animals. Furthermore, the immunized animals were totally protected against challenge with FMDV after inoculation with one dose of the VLP. These results encourage further work towards the development of a VLP vaccine against FMDV.

\section{Materials and methods}

\section{Cells and virus}

BHK-21 cells were cultured at $37^{\circ} \mathrm{C}$ in a $5 \% \mathrm{CO}_{2}$ atmosphere in Dulbecco's modified Eagle's medium (DMEM; Gibco, Invitrogen corporation, Grand Island, NY, USA) supplemented with $10 \%$ fetal bovine serum (FBS; HyClone Laboratories Inc., Victoria, Australia), $100 \mathrm{U} / \mathrm{mL}$ penicillin and $100 \mathrm{mg} / \mathrm{mL}$ streptomycin. FMDV strain Asia1/Jiangsu/ China/2005 (GenBank accession number: EF149009) was propagated in BHK21 cells.

\section{Plasmid constructions}

A SUMO fusion protein expression vector was constructed as described previously with modification [35]. This vector 
is designated as pSMK which carries a kanamycin resistant gene (KanR). A pSMA vector that carries an ampicillin resistant gene $(\mathrm{AmpR})$ and a $\mathrm{pSMC}$ vector that carries a chloramphenicol resistant gene (ChlR) were constructed by replacing KanR of the pSMK vector with AmpR and ChlR, respectively. Three FMDV capsid proteins VP0, VP1 and VP3 were amplified by polymerase chain reaction (PCR), subcloned into pSMK, pSMA and pSMC respectively. The recombinant plasmids were designated as PSMKVP0, pSMAVP1 and pSMCVP3 respectively.

\section{Protein production}

To simultaneously express the three SUMO fusion proteins in the same E. coli cells, pSMKVP0, pSMAVP1 and pSMCVP3 were transformed into E. coli BL21(DE3) (Stratagen, La Jolla, CA, USA) simultaneously and selected by Amp, Kan and Chl resistance. Expression, purification and proteolytic cleavage of His6-Smt3 fusion proteins were carried out as described before [35]. The expressed proteins were analyzed by $10 \%$ sodium dodecyl sulphate polyacrylamide gel electrophoresis (SDS-PAGE) under denaturing conditions and the specificity of the proteins was confirmed by immunoblot assay [12].

\section{VLP quantification}

A sucrose gradient ultracentrifugation method was used for analytical purpose as previously described [31]. Briefly, the proteolytically cleaved protein or inactivated virus was layered on the top of a $10 \%-30 \%(\mathrm{w} / \mathrm{v})$ sucrose gradient in NET buffer $(0.1 \mathrm{M} \mathrm{NaCl}, 0.001 \mathrm{M}$ EDTA, $0.05 \mathrm{M}$ Tris- $\mathrm{HCl}, \mathrm{pH}$ 7.5). The samples were then centrifuged at $35000 \mathrm{rpm}$ for $3 \mathrm{~h}$ using an Optima L-100 XP ultracentrifuge (Beckman Coulter, Fullerton, CA, USA). After centrifugation, the gradients were fractionated and the optimal density (OD) at $280 \mathrm{~nm}$ or $260 \mathrm{~nm}$ of each fraction was measured using UA-Visible Spectrophotometer BioMate 3S (ThermoFisher Scientific Inc. Madison, WI, USA) and the quantity of intact capsids was determined. The fraction was used for electron microscopy.

\section{Electron microscopy observation of VLP}

Samples for transmission electron microscopy (TEM) measurements were prepared by dipping a drop of the purified protein complex onto Formvar coated copper grids (300 mesh, Pelco, CA, USA) at room temperature. The grid was then removed, and excess liquid was drained off by blotting the edge of the grid with a piece of clean filter paper. Next, the grid was floated on a drop of $2 \%$ phosphotungstic acid ( $\mathrm{pH}$ 6.5) for 1 min and airdried for a few minutes after the excess phosphotungstic acid was removed as before. TEM images were recorded on a JEOL 2010 transmission electron microscope operated at an acceleration voltage of $100 \mathrm{kV}$.

\section{Animal immunization and challenge protocols}

Fifteen guinea pigs weighing 400-500 g were obtained from the laboratory animal center of Lanzhou veterinary research institute, China. All the animals were fed in an isolated hutch. The guinea pigs were randomly divided into three groups of 5 animals each: group A, inactivated FMDV serotype Asia1; Group B, FMD VLP; Group C, phosphate buffered saline (PBS, $\mathrm{pH} 7.4$ ). The guinea pigs were injected with $0.2 \mathrm{~mL}$ inactivated FMDV or $50 \mu \mathrm{g}$ FMD VLP together with unassembled proteins emulsified by freund complete adjuvant or $0.2 \mathrm{~mL}$ PBS in the tibialis cranialis muscle of both rear legs. The serum samples were taken from the heart at 28 days postimmunization (dpi) after guinea pigs were anesthetized with pentobarbital sodium. All guinea pigs were subcutaneously and intradermally challenged with $0.2 \mathrm{~mL}$ 100 times $50 \%$ infective dose $\left(100 \mathrm{ID}_{50}\right)$ per guinea pig of homologous live virus on left back sole at $28 \mathrm{dpi}$. All guinea pigs were kept in an isolated hutch and examined for 7 days. The lesion appearing only on the left back sole was referred to as an indicator of partial protection, on both back soles as an indicator of no protection and no lesion on the back was considered as an indicator of total protection.

Thirteen 2-month-old pigs, sero-negative for FMDV, were purchased from a conventional breeding/finishing farm. All animals were housed in an animal biosafety level 3 (ABSL3) facility and divided into three groups. There are five pigs in Group A and Group B, three pigs in Group C. Group A: Inactivated FMDV serotype Asia1 $(2 \mathrm{~mL})$; Group B: FMD VLP $(50 \mu \mathrm{g})$; Group C: PBS $(2 \mathrm{~mL})$. FMDV inactivated vaccine or FMD VLP were emulsified with the adjuvant Montanide ISA 206 (Seppic, Paris, France) with a ratio of 1:1. All pigs were intramuscularly inoculated at the ear-root-neck area and bled at 10, 18 and 28 dpi. Four weeks after vaccination, all pigs were challenged by direct inoculation at the earroot-neck area with the virulent homologous virus strain Asia1/Jiangsu/China/2005 at $1000 \mathrm{ID}_{50}$ per pig. All pigs were housed in an isolated facility and examined for 10 days after challenge. The animals were examined daily for clinical signs of FMD, including the appearance of vesicles on the mouth and feet. Any lesion on the snot and feet of pigs was referred to as an indicator of no protection.

Seventeen one-year old cattle, sero-negative of FMDV, were divided into four groups. Group A: one dose of FMD VLP; Group B: 1/3 dose of FMD VLP; Group C: $1 / 9$ dose of FMD VLP; Group D: Healthy control. Except for Group D which included 2 cattle, other groups included 5 animals each. All animals were 
housed in a BSL3 facility and were immunized by intramuscular inoculation of FMD VLP emulsified with the adjuvant Montanide ISA 206 with the ratio of $1: 1$. One dose contains $50 \mu \mathrm{g}$ FMD VLP. Fifty percent protection dose $\left(\mathrm{PD}_{50}\right)$ test was performed as described by the OIE to test the potency of FMD VLP as a vaccine candidate. Vaccinated and control cattle were challenged by tongue intradermal inoculation with a homologous virus strain Asia1/Jiangsu/China/ 2005 at 10000 ID $_{50}$ per head. The animals were periodically inspected for possible occurrence of lesions in the mouth, tongue, lips, buccal mucosa, teats, and feet. Any lesion at a site in the mouth other than the inoculation site within 10 days post-challenge (dpc) was considered as a rupture of immunity and considered as no protection. Blood and serum samples were collected by standard protocols at 9, 16, 21 dpi and 2, 5, 8,10 dpc. The bovine $\mathrm{PD}_{50}$ content of the vaccine was calculated based on the Reed-Muench method from each animal protected in each group.

\section{Ethics statement}

All animals received humane care in compliance with good animal practice according to the Animal Ethics Procedures and Guidelines of the People's Republic of China. The specific experiments were approved by Animal Ethics Committee of Lanzhou Veterinary Research Institute, Chinese Academy of Agricultural Sciences (permit number LVRIAEC2011-018).

\section{Western blot analysis of animal serum}

BHK-21 cells in serum-free DMEM were infected with FMDV type Asia1/Jiangsu/China/2005 at a multiplicity of infection of 10 and incubated for several hours at $37^{\circ} \mathrm{C}$ with $5 \% \mathrm{CO}_{2}$ until a cytopathic effect (CPE) was observed by light microscopy. Cells uninfected and infected with FMDV Asia1/Jiangsu/China/2005 were harvested and frozen-thaw for three times. $5 \times$ SDS loading buffer was added in cell lysates and boiled for $10 \mathrm{~min}$. The specificity of animal serum against whole virus or VLP was confirmed by immunoblot assay using sera obtained from animals unvaccinated or vaccinated with inactivated FMD vaccine and VLP vaccine, respectively.

\section{Determination of antibody titers by ELISA}

The antibody titers in immunized guinea pigs were determined by indirect-ELISA as described elsewhere $[36,37]$. Briefly, 96-well plates were coated with inactivated FMDV Asia1/Jiangsu/China/2005 (100 mL/ well) in $0.05 \mathrm{M}$ bicarbonate buffer ( $\mathrm{pH} 9.6)$ at $4^{\circ} \mathrm{C}$ overnight. After binding of the target antigen, wells were blocked in $100 \mu \mathrm{L}$ PBST containing $1 \%$ BSA at $37^{\circ} \mathrm{C}$ for $1 \mathrm{~h}$, washed and drained. One-hundred fold dilutions of sample sera were added to the microtiter wells in $50 \mu \mathrm{L}$ of PBST-BSA and incubated for $1 \mathrm{~h}$ at $37^{\circ} \mathrm{C}$. After the sample sera were removed and washed. Horseradish peroxidase (HRP)-conjugated anti-guinea pig antibody (1:2000) (Sigma, St. Louis, MO, USA) was added and incubated for $1 \mathrm{~h}$ at $37^{\circ} \mathrm{C}$. Then the enzyme substrate o-phenylenediamine (OPD, Sigma, St. Louis, MO, USA) in $50 \mu \mathrm{L}$ sodium citrate was added to each well and incubated for $15 \mathrm{~min}$ at room temperature. The reaction was stopped with $50 \mu \mathrm{L} 2 \mathrm{M} \mathrm{H}_{2} \mathrm{SO}_{4}$, and the plate was read at $492 \mathrm{~nm}$ on a spectrophotometer (BioRad, Hercules, CA, USA). Antibody reactivity was reported as OD values.

The FMDV-specific antibody titers in immunized pigs and cattle were detected by a liquid-phase-block ELISA (LPB-ELISA) kit as described by Shao et al. [38]. Briefly, $50 \mu \mathrm{L}$ of 2 -fold serial dilution of each test serum in duplicate were prepared in U-bottom multiwell plates (Corning, NY, USA). To each well, $50 \mu \mathrm{L}$ of a constant dose of viral antigen that was used to raise the rabbit antiserum for coating the plates were added and left at $4^{\circ} \mathrm{C}$ overnight. Subsequently, $50 \mu \mathrm{L}$ of the serum-antigen mixture were transferred to an ELISA plate pre-coated with rabbit anti-FMDV serum and incubated at $37^{\circ} \mathrm{C}$ for $1 \mathrm{~h}$ at a dilution of 1:1000. After thorough washing with PBST, $50 \mu \mathrm{L}$ of guinea-pig antiserum was added to each well and the plates were incubated at $37^{\circ} \mathrm{C}$ for $1 \mathrm{~h}$. The plates were washed five times with $\mathrm{PBST}$, followed by the addition of $50 \mu \mathrm{L}$ of rabbit anti-guinea pig IgG-HRP at a dilution of 1:2000 (Sigma) and incubated at $37^{\circ} \mathrm{C}$ for $1 \mathrm{~h}$. Then, the enzyme substrate o-phenylenediamine (Sigma) was added to each well for 10 to $15 \mathrm{~min}$ of incubation after being washed and drained. The reaction was terminated with $2 \mathrm{M} \mathrm{H}_{2} \mathrm{SO}_{4}$, and the plate was read at $492 \mathrm{~nm}$ on a spectrophotometer (BioRad, Hercules). Antibody titer was reported as $\log 10$ of the reciprocal of the highest dilution.

\section{Serum neutralization assay}

Serum samples collected from animals at different time points were heat-inactivated $\left(30 \mathrm{~min}, 56^{\circ} \mathrm{C}\right)$ and used in a microtiter neutralization assay on BHK-21 cells. Serial dilutions of serum were incubated with $100 \mathrm{TCID}_{50}$ of FMDV strain Asia1/Jiangsu/China $/ 2005$ at $37^{\circ} \mathrm{C}$ and $5 \%$ $\mathrm{CO}_{2}$ for $1 \mathrm{~h}$, followed by infection of monolayers of BHK-21 cells in 96-well plates for $72 \mathrm{~h}$. Thereafter, the cells were examined for FMDV-specific cytopathic effect and neutralization titers were calculated as $\log 10$ of the reciprocal of the highest dilution resulting in 50\% neutralization [36].

\section{Lymphocyte proliferation assay}

The T-lymphocyte proliferation assay was performed with the Cell Titer 96AQueous Non-Radioactive Cell 
Proliferation Assay (Promega, Madison, WI, USA). Five guinea pigs from each group were sacrificed and single lymphocyte suspensions were prepared from spleens at 28 dpi as described previously [36,37]. Peripheral blood mononuclear cells (PBMC) were isolated from pigs at 28 dpi or cattle at 21 dpi by centrifugation in Ficoll-Paque Plus (density 1.077; Amersham Biosciences, Corston, UK) at room temperature for $30 \mathrm{~min}$. Mononuclear cells were collected from the buffy coat and centrifuged, and residual red blood cells were lysed by incubation in water for $1 \mathrm{~min}$ followed by the addition of Eagle's solution. After two washes in PBS, the cells were resuspended in RPMI 1640 supplemented with 25 mM HEPES, $2 \mathrm{mM}$ glutamine, 10\% FBS, penicillin/streptomycin. Lymphocyte suspensions of spleen or PBMC were added to 96well flat-bottomed plates at a concentration of $100 \mu \mathrm{L}$ per well $\left(2 \times 10^{5}\right.$ cells per well). Subsequently, $100 \mu \mathrm{L}$ per well of medium with or without inactivated FMDV Asia1/Jiangsu/China/2005 (10 $\mu \mathrm{g} / \mathrm{mL})$ was added and mixed. Each sample was tested in triplicate. Phytohaemagglutinin (PHA) (Sigma) at the final concentration of $10 \mu \mathrm{g} / \mathrm{mL}$ was used as a positive control. The plates were incubated at $37^{\circ} \mathrm{C}$ for $60 \mathrm{~h}$ followed by incubation with a tetrazolium compound [3-(4,5-dimethyl-2yl) -5- (3-carboxymethoxyphenyl)-2-(4-sulfophenyl)$2 \mathrm{H}$-tetrazolium, inner salt; MTS] and then incubated at $37^{\circ} \mathrm{C}$ under $5 \% \mathrm{CO}_{2}$ for $4 \mathrm{~h}$. The absorbance at $490 \mathrm{~nm}$ was measured with a spectrophotometer (BioRad, Hercules, CA, USA). Data are expressed as stimulation index $(\mathrm{SI})$, calculated as the mean reading of triplicate wells of antigen-stimulated cells divided by the mean reading of triplicate wells from unstimulated (negative control) wells.

\section{Analysis of cytokine IFN- $\gamma$}

Spleen lymphocyte or PBMC supernatants were cultured with $10 \mu \mathrm{g} / \mathrm{mL}$ of inactivated FMDV Asia1/Jiangsu/ China/2005 for $72 \mathrm{~h}$ and analyzed for cytokine IFN- $\gamma$ expression using commercially available guinea pig, porcine, bovine IFN- $\gamma$ ELISA kits (Uscn Life Science, Wuhan, China) by following the instructions supplied. The concentration of IFN- $\gamma$ in the samples is then determined by comparing the O.D. of the samples to the standard curve.

\section{Virus infectivity assay}

The presence of virus in serum was determined by a standard plaque assay on BHK-21 cells. Briefly, confluent monolayers of cells on six-well plates were adsorbed with serial dilutions of serum samples. Following adsorption at $37^{\circ} \mathrm{C}$ for $1 \mathrm{~h}$, the samples were removed and cells were washed twice with PBS ( $\mathrm{pH}, 7.4)$. Then, $2 \mathrm{~mL}$ of DMEM containing $1 \%$ agarose gel were added and incubated at $37^{\circ} \mathrm{C}$ in a humidified atmosphere containing $5 \%$
$\mathrm{CO}_{2}$ for $24 \mathrm{~h}$. Cells treated with samples were stained with a neutral red solution to visualize the plaques. Virus titers were expressed as log10 PFU per mL.

\section{Detection of FMDV RNA by real time RT-PCR}

Frozen serum samples from animals were thawed and processed for RNA extraction and measurement of specific FMDV RNA by real-time reverse transcription-PCR (RT-PCR) as previously described. Real time RT-PCR was performed using a Mx3005P sequence detection system (Agilent, Santa Clara, CA, USA). Samples were considered negative when FMDV RNA molecules/mL were less than $10^{3}[39,40]$.

\section{Statistical analysis}

Data are presented as mean \pm SD. The statistical analysis was first performed to verify the homogeneity of variance by using the Levene test. Then, the analysis of variance between groups using One-way ANOVA was applied. Finally, a comparison of mean pair wise differences between groups using Least Significance Difference (LSD) was performed. Significance of all statistical tests was set at $0.05(p<0.05)$.

\section{Results}

\section{Construction and expression of soluble His6-SM FMDV \\ capsid proteins}

Three components of the structural proteins of FMDV, VP0, VP1 and VP3, cleaved from the P1 protein precursor, can remain associated in a protein complex and act as a monomer for the self-assembly of five monomers into the pentameric capsid subunit. Further assembly of 12 pentamers and a molecule of genomic RNA generates a provirion [41,42], which subsequently undergoes maturation cleavage to convert VP0 into VP2 and VP4 to produce the mature infectious virion [43-45]. However, FMDV has the ability to form empty capsids sharing the same antigenicity as virions, but does not contain RNA and cleaved VP0 [46-48]. To express the three structural proteins and to further facilitate the assembly of FMD VLP, recombinant plasmids encoding VP0 (pSMKVP0), VP1 (pSMAVP1) and VP3 (pSMCVP3) were constructed. These three vectors expressing SUMO fusion proteins were simultaneously transformed and induced to express in the same E. coli host cells. As shown in Figure 1A, the three SUMO fusion proteins were all strongly induced by IPTG and were water-soluble. The expression efficiency was further improved by incubation at $16^{\circ} \mathrm{C}$ overnight, compared with the conditions at $37^{\circ} \mathrm{C}$ for $3-4 \mathrm{~h}$ (data not shown). The yield of the purified protein produced by the recombinant bacterial clone varied between 15-20 mg/L culture, which is significantly higher than the purified protein produced by the scheme described previously [21]. The molecular 

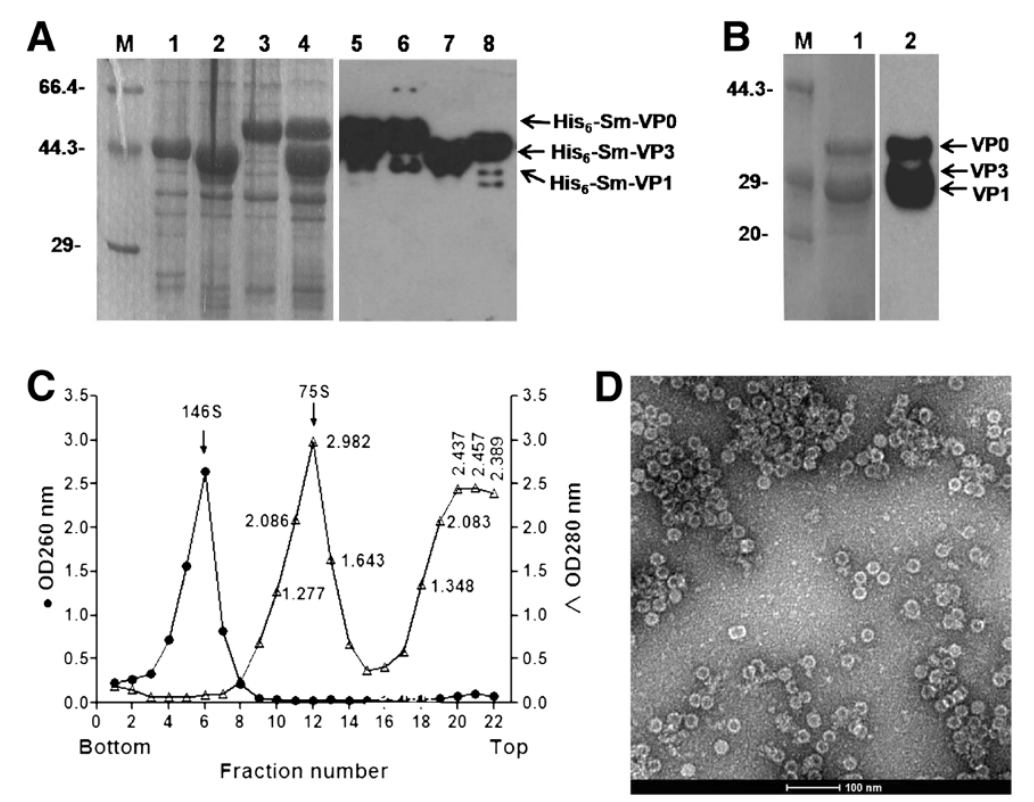

Figure 1 Expression and assembly of purified FMDV capsid proteins. (A) SDS-PAGE (left panel, lanes M, 1-4) and Western blot (right panel, lanes 5-8) analysis of the purified capsid protein complexes without Ulp1 protease treatment, including the SUMO-tagged FMDV VP3 protein expressed individually (lanes 1 and 8), the SUMO-tagged FMDV VP1 protein expressed individually (lanes 2 and 7), the SUMO-tagged FMDV VPO protein expressed individually (lanes 3 and 6) and the three SUMO-tagged protein complex simultaneously expressed (lanes 4 and 5).

(B) SDS-PAGE (lane 1) and Western blot (lane 2) analysis of the purified three SUMO-tagged protein complex after protease digestion and the second affinity chromatography. (C) Purification and analysis of FMD VLP by sucrose gradient ultracentrifugation. The purified three capsid proteins were loaded onto a 10\%-30\% (w/v) sucrose gradient. After centrifugation, 20 fractions were collected and measured at $280 \mathrm{~nm}$ using UA-Visible Spectrophotometer BioMate $3 S$ (ThermoFisher Scientific Inc. USA) and the quantity of capsid proteins in each fraction was determined and plotted. (D) Negative staining electron microscopy of FMD VLP containing purified VPO, VP3 and VP1. Scale bar, $100 \mathrm{~nm}$.

masses of His6-Sm-VP0, His6-Sm-VP1 and His6-Sm-VP3 fusion protein are approximately 45,35 and $36 \mathrm{kDa}$, respectively (Figure 1A). So, the latter two protein bands were not well separated (Figure 1A, lane 4 and 5).

Extracts containing the coexpressed SUMO fusion proteins were purified on $\mathrm{Ni}_{2}^{+}$-resin and then treated with SUMO protease to remove the His6-Sm moieties. The cleavage products contained three water soluble polypeptides with molecular weights about $33 \mathrm{kDa}$ (VP0), $24 \mathrm{kDa}$ (VP3) and $23 \mathrm{kDa}$ (VP1) and His6-Sm tag, respectively, upon examination by SDS-PAGE (data not shown). After purification of the cleavage products by $\mathrm{Ni}_{2}^{+}$-resin again, the three fusion proteins were left in solution (Figure 1A).

\section{VLP assembly and quantification}

To demonstrate if the expressed FMDV capsid proteins could assemble into empty particles, the proteolytically cleaved proteins were analyzed by sedimentation on a $10 \%-30 \%$ sucrose gradient. Fractions were collected and measured with a spectrophotometer. The results (Figure 1C) show the presence of a peak corresponding to $75 \mathrm{~S}$ empty capsid particles from FMDV $[12,31]$. The peak fractions were pooled and the percentage of VLP was calculated from the peak area. This portion was approximately $43 \%$ of the total expressed proteins (Figure 1C), while the other $57 \%$ of proteins failed to assemble into stable empty capsids, as they remained near the top of the gradient (Figure 1C).

Transmission electron microscopy was then used to examine the extent of VLP assembly by these ternary protein complexes. As shown in Figure 1D, the VP0-VP1 -VP3 complexes formed uniform round VLP aggregates with a diameter about $25 \mathrm{~nm}$, which is similar to the average diameter of $25 \mathrm{~nm}$ of the authentic FMDV particles.

\section{Immunization with FMD VLP induces specific protective responses in guinea pigs}

Guinea pigs are one of the ideal experimental animals for FMDV study and widely used for initial characterization of the antigenic properties of FMD vaccine candidates. To determine if FMD VLP could stimulate anti-FMDV immune responses in guinea pigs, groups of five guinea pigs were immunized with FMD VLP intramuscularly and two other groups of five animals were immunized with inactivated FMDV as a positive control and PBS as a negative control, respectively. The results show that FMDVspecific antibodies, neutralizing antibodies, specific T-cell response and IFN- $\gamma$ responses were efficiently induced by 
immunization with FMD VLP. Significant differences were observed between guinea pigs inoculated with PBS and with either FMD VLP or FMD inactivated vaccine, however, no significant difference was found between guinea pigs inoculated with the FMD VLP and FMD inactivated vaccine.

After challenge with 100 ID $_{50}$ FMDV Asia1/China/ Jiangsu/2005 per guinea pig, all of the control animals inoculated with PBS showed typical symptoms on both back feet at $2 \mathrm{dpc}$, as expected. In contrast, none of the guinea pigs vaccinated with the inactivated FMD vaccine and the FMD VLP developed any symptom associated with FMDV replication.

\section{Immunization with FMD VLP induces specific protective responses in pigs}

The efficiency of FMD VLP as a potent FMD vaccine candidate in guinea pigs prompted us to investigate the effectiveness of FMD VLP as a vaccine in pigs, one of the natural hosts of FMDV [49]. The FMDV-specific antibody responses were quantified by LPB-ELISA in pigs inoculated with FMD VLP. Compared to the control group inoculated with PBS, the presence of specific antibodies was detected at $10 \mathrm{dpi}$ in all inoculated animals, and the level of specific antibodies increased and remained at a high level until $28 \mathrm{dpi}$ (Figure 2A). FMDVspecific neutralizing antibodies were found in sera from pigs inoculated with the inactivated FMDV vaccine and the FMD VLP at $10 \mathrm{dpi}$ (Figure 2A). All animals in the two groups showed high neutralization titers after the vaccine administration. Subsequently, the titers were further increased and remained at a high level until challenge (28 dpi), like the specific FMDV antibodies (Figure 2B). The average levels of the specific and the neutralizing antibodies in pigs inoculated with FMD VLP are similar to those in the group inoculated with the inactivated FMDV (Figure 2A and B), suggesting that FMD VLP are competent to induce specific humoral immune response as the whole FMDV particles in pigs.

FMDV specific T-cell responses were detected in all animals vaccinated with both the FMD VLP and the inactivated FMDV at $28 \mathrm{dpi}$. Although individual pigs showed high levels of $\mathrm{T}$-cell response, the average proliferative responses of all vaccinated pigs did not show a highly significant increase in the stimulation indexes, compared with the animals inoculated with PBS, which was different from the T-cell response in guinea pigs.

The induction of IFN- $\gamma$ in PBMC samples from vaccinated pigs at day 28 post-vaccination was also determined. As with the lymphoproliferative responses, secretion of IFN- $\gamma$ did not show significant increase in pigs inoculated with the FMD VLP and the inactivated FMDV, compared with the PBS control group (Figure 2C). However, the levels of IFN- $\gamma$ induction were consistent with the lymphocyte proliferative responses in individual pigs (data not shown).

The immunized pigs were challenged with $1000 \mathrm{ID}_{50}$ FMDV Asia1/China/Jiangsu/2005 per pig at $28 \mathrm{dpi}$. Three animals in the PBS control group developed clinical signs of disease on all feet, which remained for several days. In contrast, none of the animals inoculated with either the FMD VLP or the FMDV inactivated vaccine showed any clinical signs in the mouth and feet. This confirms that FMD VLP can provide efficient protection in pigs against FMDV as the conventional inactivated FMD vaccine.
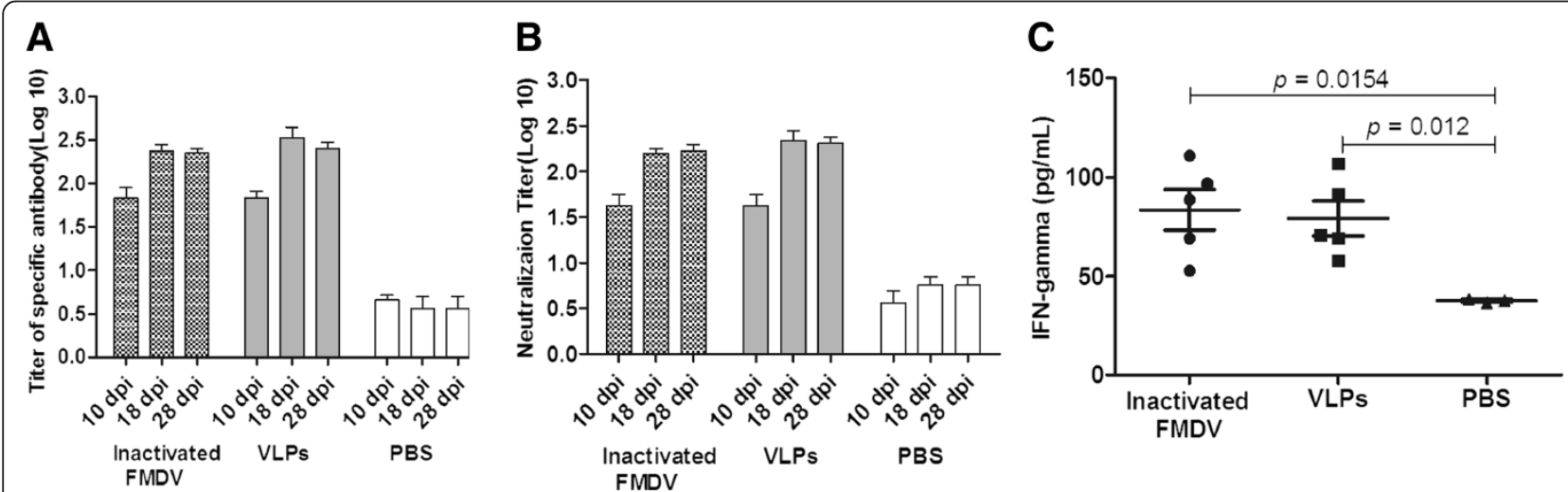

Figure 2 FMDV-specific immune responses in pigs. Groups of pigs $(n=5)$ immunized with inactivated FMDV or FMD VLP, including three PBS-inoculated pigs as a control, by intramuscular injection. Blood samples were collected at $10 \mathrm{dpi}, 18 \mathrm{dpi}$ and $28 \mathrm{dpi}$ after vaccination for virus-specific antibody response (A) and neutralizing antibody response (B). The titers of virus-specific antibody and neutralizing antibody were expressed by the average titers of pigs in one whole group at different time points. PMBC were isolated from all pigs at $28 \mathrm{dpi}$. IFN- $\gamma$ secretion (C) by PMBC was measured and is shown as $\mathrm{pg} / \mathrm{mL}$. Statistical significance among groups was compared. 


\section{Immunization with FMD VLP induces specific protective responses in cattle}

The potency of the immunity induced by the FMD VLP in cattle was evaluated as recommended in the OIE manual [50]. Three groups of cattle were inoculated with one dose, 1/3 dose and 1/9 dose of FMD VLP, and LPBE-antibody titers were determined at 9, 16, $21 \mathrm{dpi}$ and 2, 5, 8, $10 \mathrm{dpc}$, respectively. All animals vaccinated with FMD VLP developed a detectable, dose-dependent FMDV-antibody response at $9 \mathrm{dpi}$, which reached to a higher level at $16 \mathrm{dpi}$ (Figure 3A). By $21 \mathrm{dpi}$, the antibody levels were either maintained at the same level in the groups inoculated with one and $1 / 9$ dose, or slightly increased in the group inoculated with a $1 / 3$ dose (Figure 3A). Throughout this period, the antibody levels in the healthy control group remained low (Figure 3A). Except in cattle inoculated with one full dose of FMD VLP (which shows a slight increase of the antibody titer after challenge), drastic induction of specific antibody responses was observed in all other three groups of cattle after challenge at 8 and $10 \mathrm{dpc}$ (Figure 3A).

Similar patterns in serum neutralizing antibody responses were also observed. As shown in Figure 3B, the neutralizing antibody response in the group of cattle vaccinated with one dose of FMD VLP was significantly higher than that in cattle inoculated with $1 / 3$ or $1 / 9$ dose of FMD VLP, and a gradual increase of neutralizing antibody response over time was observed in most vaccinated cattle (Figure 3B). Following challenge, the neutralizing antibody titers in cattle inoculated with one dose of FMD VLP remained at the same high level, while a rapid serum-conversion was evident in the other three groups of animals vaccinated with $1 / 3$ dose, $1 / 9$ dose and healthy control at $8 \mathrm{dpc}$, respectively (Figure 3B). However, there was no statistically significant difference in titers for all the treatment groups by $10 \mathrm{dpc}$ (Figure 3B). This result was in agreement with the LPBE-antibody titers in cattle.
Dose-dependent lymphoproliferation responses were detected in all groups vaccinated with FMD VLP; however, only animals in the group inoculated with one dose and $1 / 3$ dose of FMD VLP displayed an increase in T-cell response, compared with the healthy control (data were not shown). Similarly, the production of IFN- $\gamma$ in PMBC from vaccinated cattle at $21 \mathrm{dpi}$ also displayed a significant dose-dependent induction pattern, compared with the healthy control $(p<0.05)$ (Figure 3C).

\section{Detailed evaluation of the protection potency of FMD VLP in cattle}

Animals in all groups described above were challenged by intradermal inoculation at two sites in the tongue with 10000 ID $_{50}$ FMDV Asia1/Jiangsu/China/2005 at 21 dpi. Both animals in the control group developed lesions at secondary sites of replication, including the feet, and more severe disease was seen by $2-10 \mathrm{dpc}$. All animals inoculated with one dose of FMD VLP developed a vesicle at the sites of injection only. The vesicle was selflimited and did not increase after $2 \mathrm{dpc}$. In the group inoculated with $1 / 3$ dose of FMD VLP, one animal developed a delayed lesion, which was detectable by $4 \mathrm{dpc}$ and was present on one foot. Three animals in the group inoculated with $1 / 9$ dose of FMD VLP developed lesions beyond the injection sites (Figure 4).

Viremia was evaluated in all animals by determination of the infectivity (PFUs/mL) and the FMDV RNA levels in sera. The control animals (\#4580, \#4576) developed viremia at day $1 \mathrm{dpc}$ which then lasted for 5 days (Figure 4). Cattle in the group inoculated with one dose of FMD VLP induced strong adaptive immune response, which conferred potent protection against challenge with FMDV serotype Asia1 and limited the replication of FMDV in the challenged animals. No viremia was detected in this group of animals, both by the plaque assay and by real time RT-PCT (Figure 4). Viremia was
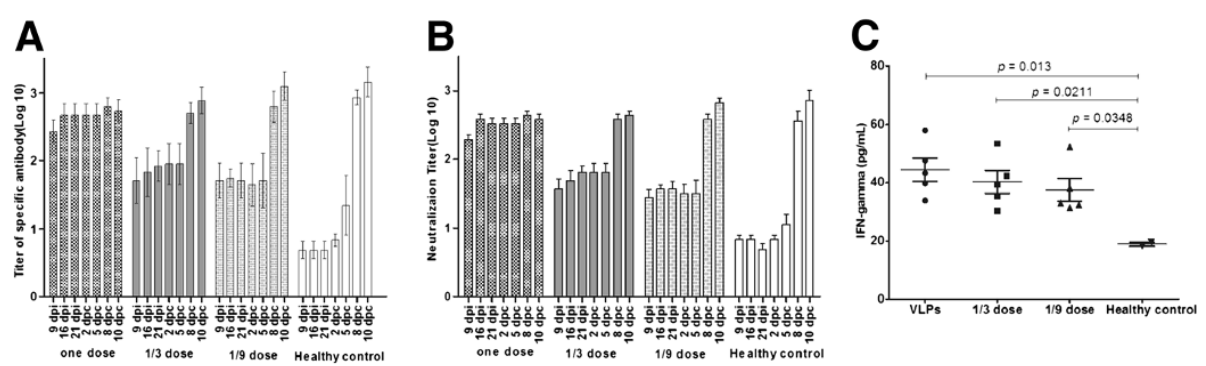

Figure 3 FMDV-specific immune responses in cattle. Groups of cattle $(n=5)$ immunized with one dose, 1/3 dose, 1/9 dose of FMD VLP, including two healthy cattle as the control, by intramuscular injection. Blood samples were collected at $9 \mathrm{dpi}, 16 \mathrm{dpi}, 21 \mathrm{dpi}$ and $2 \mathrm{dpc}, 5 \mathrm{dpc}$, $10 \mathrm{dpc}$ for virus-specific antibody response (A) and neutralizing antibody response (B). The titers of virus-specific antibody and neutralizing antibody were expressed by the average titer of cattle in one whole group at different time points. PMBC were isolated from all cattle at $21 \mathrm{dpi}$. IFN- $\gamma$ secretion (C) by PMBC was measured and shown as pg/mL. Statistical significance among groups was compared. 


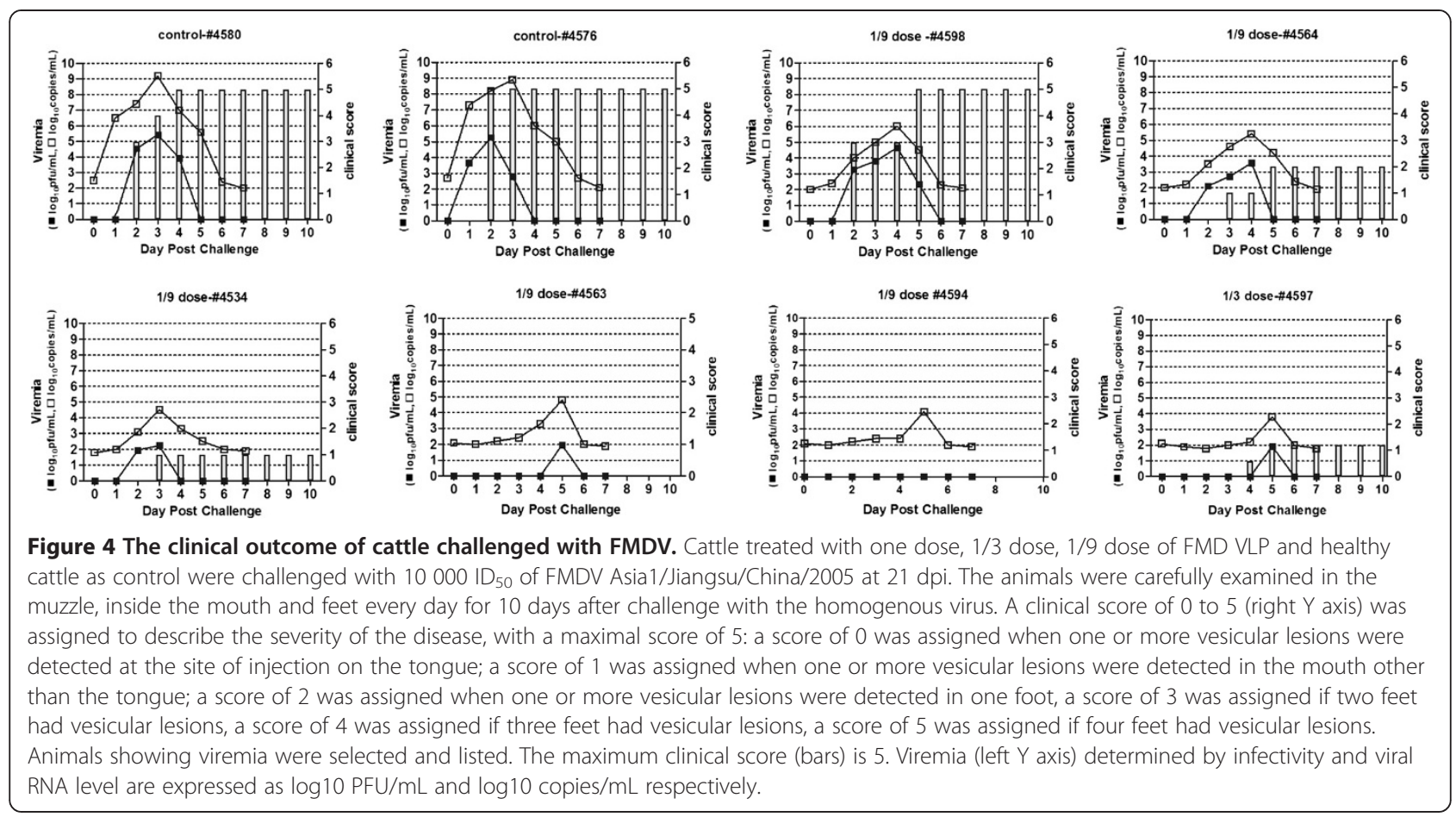

detected in one of the animals inoculated with $1 / 3$ dose of FMD VLP, but not detected in other animals in the group (Figure 4). All the animals inoculated with 1/9 dose of FMD VLP developed viremia, as detected by a plaque assay and confirmed by real-time RT-PCR, although one animal in this group did not show lesions (Figure 4). The onset of viremia in all animals in this group was delayed and the viremia lasted for a shorter period of time. The copies of FMDV RNA molecules were generally $10^{3}$ - to $10^{5}$-fold lower than in the control animals (Figure 4).

The $\mathrm{PD}_{50}$ test was then performed to assess the subunit vaccine potency following the bovine potency test protocol for traditional inactivated FMD vaccines described by the OIE. The result shows that the vaccine potency of the batch immunized with the FMD VLP reached 6.34 $\mathrm{PD}_{50}$ per dose, which was higher than that for routine prophylactic use and also meets the requirement for emergency ("ring") vaccination as specified by OIE (Table 1).

\section{Efficient induction of antibody responses by FMD VLP against the three structural proteins}

Sera from animals vaccinated with the FMD VLP and the inactivated FMDV vaccine were finally assessed by Western blot to investigate if all three structural proteins used to prepare the VLP are immunogenic. For this purpose, total cell lysates were prepared from FMDVinfected BHK-21 cells and analyzed by Western blot. The results show that sera collected from all three animal species vaccinated with FMD VLP could efficiently react with the three proteins from both virus-infected cells and FMD VLP preparation (Figure 5). Moreover, similar patterns and efficiencies of the reaction were observed from animal sera vaccinated with the inactivated FMDV (Figure 5). These results demonstrate that all three structural proteins are equally antigenic, although they are expressed and purified from a prokaryotic expression system, and further suggest that these proteins may be incorporated and assembled into VLP with an equal efficiency as well as in a correct conformation.

\section{Discussion}

In this study, we attempt to produce the FMD VLP in E. coli and use this VLP preparation as a vaccine candidate for the first time to characterize the immunological properties in a laboratory animal model and in two natural FMDV host animal species, swine and cattle.

The three SUMO fusion proteins were shown to form stable VLP with size and shape resembling the native FMDV particles, upon simultaneous expression and removal of the SUMO moiety from the SUMO-fusion proteins. The SUMO-fusion system with modification provides increased levels of expression of FMDV capsid proteins in E. coli and allows rapid purification of target proteins, by exploiting the properties that SUMO fused at the N-terminus with other proteins can fold and protect the protein by its chaperoning properties. The results of this study demonstrate that SUMO-fusion dramatically enhances the expression of the FMDV capsid 
Table 1 The neutralizing titer, T-lymphocyte proliferation and protection of cattle

\begin{tabular}{|c|c|c|c|c|c|c|c|c|}
\hline \multirow[t]{2}{*}{ Group } & \multirow[t]{2}{*}{ No } & \multicolumn{3}{|c|}{ Neutralizing titer } & \multirow{2}{*}{$\begin{array}{l}\text { T-lymphocyte proliferation (SI) } \\
\qquad 21 \mathrm{dpi}\end{array}$} & \multirow{2}{*}{$\begin{array}{l}\text { Protection } \\
10 \mathrm{dpc}\end{array}$} & \multirow[t]{2}{*}{ Rate of protection } & \multirow[t]{2}{*}{ PD50 } \\
\hline & & $9 \mathrm{dpi}$ & $16 \mathrm{dpi}$ & $21 \mathrm{dpi}$ & & & & \\
\hline \multirow[t]{5}{*}{ One dose } & $\# 4536$ & 2.408 & 2.709 & 2.107 & 1.989 & yes & $100(5 / 5)$ & 6.34 \\
\hline & \#4572 & 2.107 & 2.408 & 2.408 & 1.602 & yes & & \\
\hline & $\# 4574$ & 2.408 & 2.709 & 2.107 & 1.373 & yes & & \\
\hline & \#4590 & 2.107 & 2.408 & 2.408 & 1.586 & yes & & \\
\hline & \#4592 & 2.408 & 2.709 & 2.408 & 1.625 & yes & & \\
\hline \multirow[t]{5}{*}{$1 / 3$ dose } & \#4501 & 1.806 & 1.806 & 1.806 & 1.587 & yes & $80(4 / 5)$ & \\
\hline & $\# 4561$ & 1.204 & 1.505 & 1.806 & 1.512 & yes & & \\
\hline & $\# 4575$ & 1.806 & 2.107 & 2.107 & 1.721 & yes & & \\
\hline & \#4593 & 1.806 & 1.806 & 1.806 & 1.889 & yes & & \\
\hline & \#4597 & 1.204 & 1.204 & 1.505 & 1.353 & no & & \\
\hline \multirow[t]{5}{*}{$1 / 9$ dose } & $\# 4534$ & 1.505 & 1.505 & 1.806 & 1.351 & no & $40(2 / 5)$ & \\
\hline & $\# 4563$ & 1.505 & 1.505 & 1.204 & 1.886 & yes & & \\
\hline & $\# 4564$ & 1.204 & 1.505 & 1.505 & 1.375 & no & & \\
\hline & $\# 4594$ & 1.806 & 1.806 & 1.806 & 1.558 & yes & & \\
\hline & $\# 4598$ & 1.204 & 1.505 & 1.505 & 1.397 & no & & \\
\hline \multirow[t]{2}{*}{ Healthy cattle } & $\# 4576$ & 0.778 & 0.903 & 0.778 & 1.052 & no & $0(0 / 5)$ & \\
\hline & $\# 4580$ & 0.903 & 0.778 & 0.602 & 1.115 & no & & \\
\hline
\end{tabular}

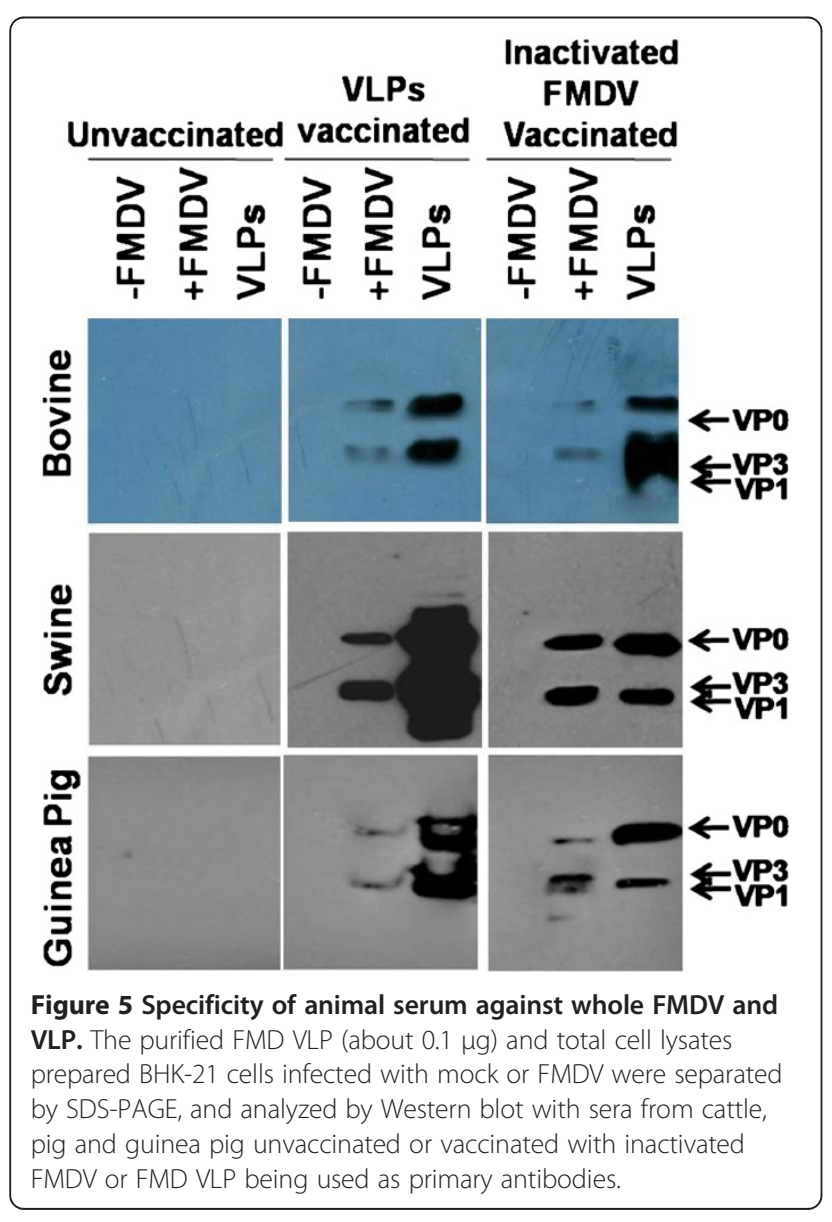

protein, which is the precondition for FMD VLP assembly. Although it is not fully understood why SUMO fusion can enhance the protein solubility, structural studies suggest that SUMO has an external hydrophilic surface and inner hydrophobic core, which may exert a detergent-like effect on otherwise insoluble proteins [30]. The next question would be whether the immunogenicity of these VLP is also similar to the FMDV native virions. Our results indicate that the FMD VLP could induce specific antibody responses against whole FMDV virions in guinea pigs, swine and cattle, as demonstrated by indirect ELISA, LPB-ELISA and Western blot analyses. This suggests that the three proteins expressed and purified from E. coli are properly folded in the VLP. In addition, the data available from mapping of the neutralizing antibody epitopes in serotype $\mathrm{O}$, the most extensively studied FMDV [51,52] and in Asia 1 by Butchaiah and Morgan [53] demonstrate that the major immunologic epitopes of serotype Asia 1 are on the surface oriented interconnecting loops between structural elements. Our observation that potent neutralizing antibody responses were induced by FMD VLP in all three vaccinated animal species demonstrates that the three proteins were not only correctly assembled into VLP but the neutralizing epitopes were also presented correctly on the surface of virus capsids. Further confirmation of the neutralizing epitopes of FMDV Asia1 together with crystallographic studies to identify the structure of the FMDV capsids would provide more insight into these issues. 
A neutralization test was carried out in this study after detection of specific antibodies against whole FMDV in sera from guinea pigs, pigs and cattle. Interestingly, the specific antibody titers in animals vaccinated with FMD VLP, as determined by indirect-ELISA and LPB-ELISA, showed a good correlation with the neutralization titers, which was consistent with the results reported previously [54,55]. Meanwhile, a good correlation between specific antibody titers and protection was also observed in this study.

Virus-induced neutralizing antibody response is crucial for the development of protection against FMD. A nice correlation between the neutralizing antibody titers and the levels of protection against live virus challenge has been found in many studies [56-58]. Similarly, neutralizing antibody responses in guinea pigs, pigs and cattle inoculated with either one or $1 / 3$ dose of the FMD VLP were shown in this study to have a positive correlation with protection against FMDV challenge. However, at 21 days post vaccination (pre-challenge) in cattle, one of the animals (\#4563) inoculated with 1/9 dose of FMD VLP was shown to have an antibody titer lower than the threshold titer, but showed resistance to challenge; whereas another one (\#4534) with a higher titer did not. This may suggest that the correlation between virus neutralization titer and protection could mainly depend on the dose of FMD VLP used in addition to the possibility of an individual variation in resistance to infection by the virus. This correlation may be proportional within a certain range of dosage. If the dose is too low, no correlation between virus neutralization titer and protection would be observed, as in the case when cattle were vaccinated with 1/9 dose of VLP (\#4563 and \#4534). Other factors, including batch and strain of FMD vaccine used, the route of inoculation, the virus titer for challenge, and so on, could also affect the correlation between the protection rate and the specific antibody/neutralizing antibody titer.

Certain non-antibody-mediated immune mechanisms, such as T-cell activation and the cytokines they release, may also play a role [59]. The results of $\mathrm{T}$ lymphocyte proliferation response and cytokine release in animals vaccinated in this study suggest that $50 \mu \mathrm{g}$ FMD VLP is enough to induce the T-lymphocyte proliferation response and induction of IFN- $\gamma$ in the guinea pig, pig and cattle. When the dose is too low to induce sufficient protective neutralizing titers, the T-cell response would promote protection against the virus infection initially provided by neutralizing antibodies. Although the T-cell response and IFN- $\gamma$ secretion in pigs and cattle did not increase as significantly as shown in guinea pigs, a correlation between $\mathrm{T}$-cell response and IFN- $\gamma$ secretion was observed in all vaccinated animals. It is assumed that optimal IFN- $\gamma$ production requires the inclusion of an efficient T-cell epitope in a suitable configuration. IFN- $\gamma$ is a major activator of macrophages, enhancing their antimicrobial activity and their capacity for processing and presenting antigens to $\mathrm{T}$ lymphocytes [60]. It has been reported that IFN- $\gamma$ stimulates MHC expression in antigen-presenting cells and efficiently inhibits FMDV replication [61]. Therefore, better clinical protection conferred by the FMD VLP in this study, especially when no sufficient neutralizing antibody response was elicited, would be due to an efficient lymphoproliferative response and IFN- $\gamma$ release. Further biochemical studies are required to understand the cooperative, redundant, or synergistic effects in the antiviral properties of T-cell response and this cytokine induced by FMD VLP.

The development of lesions and viremia in FMD VLPinoculated cattle challenged with FMDV appears to follow a dose-dependent response pattern. One dose of the $50 \mu \mathrm{g}$ FMD VLP efficiently prevented the development of disease, when the animals were exposed to the virus by direct inoculation in the epithelia of the tongue as recommended by the OIE in efficacy testing [50]. Most animals (4/5) treated with 1/3 dose of FMD VLP also did not develop lesions; only one animal in this group with a lower neutralizing antibody response showed mild lesions and short-lived viremia. Two animals vaccinated with 1/9 dose of FMD VLP had a slight delay in the appearance of viremia and development of the disease, compared to the control animals. In general, a good correlation between the development of viremia and the neutralizing antibody response was observed after FMDV challenge within the groups of cattle.

The $\mathrm{PD}_{50}$ value of the VLP vaccine is calculated from the number of cattle protected in each group. According to the OIE manual [50], when employed for routine prophylactic use, the FMD vaccine should contain at least 3 PD50 per dose for cattle. But for emergency vaccination, it should have 6 PD50 per dose for cattle. In our study, the FMD VLP contain 6.43 PD50 per dose for cattle, illustrating the potency of FMD VLP as a potential emergency vaccine. On the contrary, FMD VLP can prevent the development of local tongue lesions at the site of challenge, indicating high potency of FMD VLP as one of the vaccine formats. In addition, since potency resulting from cattle tests can be a good indicator for the vaccine applicability in other species, the potency of FMD VLP could be sufficient to endorse its use in pigs, which is the reason why the potency test in swine was not carried out.

Taken together, our present results show the potential of using FMD VLP produced in E. coli as a vaccine candidate. Vaccination with a single injection of $50 \mu \mathrm{g}$ of proteins could elicit a high level of immune response, which is sufficient to protect guinea pigs, swine and cattle from virulent virus infection. 


\section{Competing interests}

The authors declare that they have no competing interests.

\section{Authors' contributions}

GHC and SSQ carried out most of the experiments and drafted the manuscript. LXT, LDX, YH and LXX critically revised the experiment design and manuscript. JY, YSL, YSH, SDH, WYQ and MJU helped with the experiment. LZX and GJH helped with the addition experiment and revision of this manuscript. All authors read and approved the final manuscript.

\section{Acknowledgements}

This research was supported in part by grants from the national science and technology support program (2013BAD12B05), Gansu Provincial Sci. \& Tech. Department (No. 1102NKDA033; No.1102NKDA034; No.1104WCGA185), Ministry of Science and Technology of the People's Republic of China (2011AA10A211-4) and the Scientific Research Foundation for the Returned Overseas Chinese Scholars, State Education Ministry. We are thankful to Lü Lü, Juan Chen and Jijun He for helping in assaying the challenge of animals. We also thank Juan Song for detection of LPB-ELSA, Yingde Shao and Jincai Yang for preparation of virus.

Received: 19 October 2012 Accepted: 31 May 2013

Published: 4 July 2013

\section{References}

1. Alexandersen S, Mowat N: Foot-and-mouth disease: host range and pathogenesis. Curr Top Microbiol Immunol 2005, 288:9-42.

2. Baxt B, Rieder E: Molecular aspects of foot-and-mouth disease virus virulence and host range: role of host cell receptors and viral factors. In Foot and mouth disease: current perspectives. Edited by Sobrino F, Domingo E. Norfolk: Horizon Bioscience; 2004:145-172.

3. Yang PC, Chu RM, Chung WB, Sung HT: Epidemiological characteristics and financial costs of the 1997 foot-and-mouth disease epidemic in Taiwan. Vet Rec 1999, 145:731-734.

4. Alexandersen S, Kitching RP, Mansley LM, Donaldson Al: Clinical and laboratory investigations of five outbreaks of foot-and-mouth disease during the 2001 epidemic in the United Kingdom. Vet Rec 2003, 152:489-496.

5. Thompson D, Muriel P, Russell D, Osborne P, Bromley A, Rowland M, CreighTyte S, Brown C: Economic costs of the foot and mouth disease outbreak in the United Kingdom in 2001. Rev Sci Tech 2002, 21:675-687.

6. Grubman MJ, Baxt B: Foot-and-mouth disease. Clin Microbiol Rev 2004, 17:465-493.

7. Sutmoller P, Barteling SS, Olascoaga RC, Sumption KJ: Control and eradication of foot-and-mouth disease. Virus Res 2003, 91:101-144.

8. Jennings GT, Bachmann MF: The coming of age of virus-like particle vaccines. Biol Chem 2008, 389:521-536.

9. Johnson JE, Chiu W: Structures of virus and virus-like particles. Curr Opin Struct Biol 2000, 10:229-235.

10. Grgacic EVL, Anderson DA: Virus-like particles: passport to immune recognition. Methods 2006, 40:60-65.

11. Li Z, Yi Y, Yin $X$, Zhang Z, Liu J: Expression of foot-and-mouth disease virus capsid proteins in silkworm-baculovirus expression system and its utilization as a subunit vaccine. PLoS One 2008, 3:e2273.

12. Cao Y, Lu Z, Sun J, Bai X, Sun P, Bao H, Chen Y, Guo J, Li D, Liu X, Liu Z: Synthesis of empty capsid-like particles of Asia I foot-and-mouth disease virus in insect cells and their immunogenicity in guinea pigs. Vet Microbiol 2009, 137:10-17.

13. Mohana Subramanian B, Madhanmohan M, Sriraman R, Chandrasekhar Reddy RV, Yuvaraj S, Manikumar K, Rajalakshmi S, Nagendrakumar SB, Rana SK, Srinivasan VA: Development of foot-and-mouth disease virus (FMDV) serotype $O$ virus-like-particles (VLPs) vaccine and evaluation of its potency. Antiviral Res 2012, 96:288-295.

14. Li Z, Yi Y, Yin X, Zhang Y, Liu M, Liu H, Li X, Li Y, Zhang Z, Liu J: Development of a foot-and-mouth disease virus serotype A empty capsid subunit vaccine using silkworm (Bombyx mori) pupae. PLoS One 2012, 7:e43849.

15. Li Z, Yin X, Yi Y, Li X, Li B, Lan X, Zhang Z, Liu J: FMD subunit vaccine produced using a silkworm-baculovirus expression system: protective efficacy against two type Asia1 isolates in cattle. Vet Microbiol 2011, 149:99-103.
16. Grubman MJ: Development of novel strategies to control foot-and-mouth disease: marker vaccines and antivirals. Biologicals 2005, 33:227-234.

17. Lu Z, Bao H, Cao Y, Sun P, Guo J, Li P, Bai X, Chen Y, Xie B, Li D, Liu Z, Xie Q: Protection of guinea pigs and swine by a recombinant adenovirus expressing $\mathrm{O}$ serotype of foot-and-mouth disease virus whole capsid and 3C protease. Vaccine 2008, 26(Suppl 6):G48-G53.

18. Moraes MP, Mayr GA, Mason PW, Grubman MJ: Early protection against homologous challenge after a single dose of replication-defective human adenovirus type 5 expressing capsid proteins of foot-and-mouth disease virus (FMDV) strain A24. Vaccine 2002, 20:1631-1639.

19. Pacheco JM, Brum MC, Moraes MP, Golde WT, Grubman MJ: Rapid protection of cattle from direct challenge with foot-and-mouth disease virus (FMDV) by a single inoculation with an adenovirus-vectored FMDV subunit vaccine. Virology 2005, 337:205-209.

20. Grubman MJ, Moraes MP, Neilan J, Ettyreddy D, Butman BT, Brough DE, Brake DA: Adenovirus serotype 5 vectored foot-and-mouth disease subunit vaccines: the first decade. Future Virol 2010, 5:51-64.

21. Lee CD, Yan YP, Liang SM, Wang TF: Production of FMDV virus-like particles by a SUMO fusion protein approach in Escherichia coli. J Biomed Sci 2009, 16:69.

22. Waldo GS, Standish BM, Berendzen J, Terwilliger TC: Rapid protein-folding assay using green fluorescent protein. Nat Biotechnol 1999, 17:691-695.

23. Studier FW, Moffatt BA: Use of bacteriophage T7 RNA polymerase to direct selective high-level expression of cloned genes. J Mol Biol 1986, 189:113-130.

24. Ikura K, Kokubu T, Natsuka S, Ichikawa A, Adachi M, Nishihara K, Yanagi H, Utsumi S: Co-overexpression of folding modulators improves the solubility of the recombinant guinea pig liver transglutaminase expressed in Escherichia coli. Prep Biochem Biotechnol 2002, 32:189-205.

25. Nilsson J, Stahl S, Lundeberg J, Uhlen M, Nygren PA: Affinity fusion strategies for detection, purification, and immobilization of recombinant proteins. Protein Expr Purif 1997, 11:1-16.

26. Catanzariti AM, Soboleva TA, Jans DA, Board PG, Baker RT: An efficient system for high-level expression and easy purification of authentic recombinant proteins. Protein Sci 2004, 13:1331-1339.

27. De Marco V, Stier G, Blandin S, De Marco A: The solubility and stability of recombinant proteins are increased by their fusion to NusA. Biochem Biophys Res Commun 2004, 322:766-771.

28. Wang C, Castro AF, Wilkes DM, Altenberg GA: Expression and purification of the first nucleotide-binding domain and linker region of human multidrug resistance gene product: comparison of fusions to glutathione S-transferase, thioredoxin and maltose binding protein. Biochem J 1999, 338:77-81.

29. Pryor KD, Leiting B: High-level expression of soluble protein in Escherichia coli using a His6-tag and maltose-binding-protein double-affinity fusion system. Protein Expr Purif 1997, 10:309-319.

30. Malakhov MP, Mattern MR, Malakhova OA, Drinker M, Weeks SD, Butt TR: SUMO fusions and SUMO-specific protease for efficient expression and purification of proteins. J Struct Funct Genomics 2004, 5:75-86.

31. Abrams CC, King AMQ, Belsham GJ: Assembly of foot-and-mouth-disease virus empty capsids synthesized by a vaccinia virus expression system. J Gen Virol 1995, 76:3089-3098.

32. Ryan MD, Belsham GJ, King AMQ: Specificity of enzyme-substrate interactions in foot-and-mouth disease virus polyprotein processing. Virology 1989, 173:35-45.

33. Belsham GJ, Brangwyn JK, Ryan MD, Abrams CC, King AMQ: Intracellular expression and processing of foot-and-mouth disease virus capsid precursors using vaccinia virus vectors influence of the I protease. Virology 1990, 176:524-530.

34. Cao Y, Sun P, Fu Y, Bai X, Tian F, Liu X, Lu Z, Liu Z: Formation of virus-like particles from 0 -type foot-and-mouth disease virus in insect cells using codon-optimized synthetic genes. Biotechnol Lett 2010, 32:1223-1229.

35. Yin S, Sun S, Yang S, Shang Y, Cai X, Liu X: Self-assembly of virus-like particles of porcine circovirus type 2 capsid protein expressed from Escherichia coli. Virol J 2010, 7:166.

36. Guo H, Liu Z, Sun S, Bao H, Chen Y, Liu X, Xie Q: Immune response in guinea pigs vaccinated with DNA vaccine of foot-and-mouth disease virus O/China99. Vaccine 2005, 23:3236-3242.

37. Guo HC, Liu ZX, Sun SQ, Leng QW, Li D, Liu XT, Xie QG: The effect of bovine IFN- $\gamma$ on the immune response in guinea pigs vaccinated with DNA vaccine of foot-and-mouth disease virus. Acta Biochim Biophys Sin (Shanghai) 2004, 36:701-706. 
38. Shao JJ, Wang JF, Chang HY, Liu JX: Immune potential of a novel multiple-epitope vaccine to FMDV type Asia 1 in guinea pigs and sheep. Virol Sin 2011, 26:190-197.

39. Reid SM, Grierson SS, Ferris NP, Hutchings GH, Alexandersen S: Evaluation of automated RT-PCR to accelerate the laboratory diagnosis of foot-and -mouth disease virus. J Virol Methods 2003, 107:129-139.

40. Rodriguez-Calvo T, Ojosnegros S, Sanz-Ramos M, Garcia-Arriaza J, Escarmis C, Domingo E, Sevilla N: New vaccine design based on defective genomes that combines features of attenuated and inactivated vaccines. PLOS One 2010, 5:e10414.

41. Ansardi DC, Morrow CD: Amino-acid substitutions in the poliovirus maturation cleavage site affect assembly and result in accumulation of provirions. J Virol 1995, 69:1540-1547.

42. Lee WM, Monroe SS, Rueckert RR: Role of maturation cleavage in infectivity of picornaviruses: activation of an infectosome. J Virol 1993, 67:2110-2122

43. Basavappa R, Syed R, Flore O, Icenogle JP, Filman DJ, Hogle JM: Role and mechanism of the maturation cleavage of VPO in poliovirus assembly: structure of the empty capsid assembly intermediate at 2.9 A resolution. Protein Sci 1994, 3:1651-1669.

44. Hindiyeh M, Li Q-H, Basavappa R, Hogle JM, Chow M: Poliovirus mutants at histidine 195 of VP2 do not cleave VPO into VP2 and VP4. J Virol 1999, 73:9072-9079.

45. Knipe T, Rieder E, Baxt B, Ward G, Mason PW: Characterization of synthetic foot-and-mouth disease virus provirions separates acid-mediated disassembly from infectivity. J Virol 1997, 71:2851-2856.

46. Rombaut $B$, Foriers A, Boeye A: In-vitro assembly of poliovirus $14 \mathrm{~s}$ subunits identification of the assembly promoting activity of infected cell extracts. Virology 1991, 180:781-787.

47. Curry S, Fry E, Blakemore W, Abu-Ghazaleh R, Jackson T, King A, Lea S, Newman J, Stuart D: Dissecting the roles of VPO cleavage and RNA packaging in picornavirus capsid stabilization: the structure of empty capsids of foot-and-mouth disease virus. J Virol 1997, 71:9743-9752.

48. Rweyemamu MM, Terry G, Pay TWF: Stability and immunogenicity of empty particles of foot-and-mouth disease virus. Arch Virol 1979, 59:69-79.

49. Zhang Q, Li D, Liu X, Liu Z, Cai X, Wu G, Qi S, Yang S, Yan X, Shang Y, He J, Ma J, Li J, Ma W, Han R, Liu X, Zhang J, Xie Q, Zhang Z: Experimental studies with foot-and-mouth disease virus type Asia-1, responsible for the 2005 epidemic in China. Res Vet Sci 2008, 85:368-371.

50. World Organisation for Animal Health: Manual of diagnostic tests and vaccines for terrestrial animals. Paris: World Organisation for Animal Health; 2012.

51. Parry NR, Barnett PV, Ouldridge EJ, Rowlands DJ, Brown F: Neutralizing epitopes of type $O$ foot-and-mouth disease virus. II. Mapping three conformational sites with synthetic peptide reagents. J Gen Virol 1989, 70:1493-1503.

52. Barnett PV, Ouldridge EJ, Rowlands DJ, Brown F, Parry NR: Neutralizing epitopes of type $\mathrm{O}$ foot-and-mouth disease virus. I. Identification and characterization of three functionally independent, conformational sites. J Gen Virol 1989, 70:1483-1491.

53. Butchaiah G, Morgan DO: Neutralization antigenic sites on type Asia-1 foot-and-mouth disease virus defined by monoclonal antibody-resistant variants. Virus Res 1997, 52:183-194.

54. Hamblin C, Barnett ITR, Crowther JR: A new enzyme-linked immunosorbent assay (ELISA) for the detection of antibodies against foot-and-mouth disease virus. II. Application. J Immunol Methods 1986 93:123-129.

55. Hamblin C, Burnett ITR, Hedger RS: A new enzyme-linked immunosorbent assay (ELISA) for the detection of antibodies against foot-and-mouth disease virus. I. Development and method of ELISA. J Immunol Methods 1986, 93:115-121.

56. Black L, Francis MJ, Rweyemamu MM, Umehara O, Boge A: The relationship between serum antibody titres and protection from foot and mouth disease in pigs after oil emulsion vaccination. J Bio/ Stand 1984, 12:379-389.

57. Trautman $\mathrm{R}$, Bennett CE: Relationship between virus neutralization and serum protection bioassays for IgG and IgM antibodies to foot-and -mouth disease virus. J Gen Virol 1979, 42:457-466.

58. Jin HL, Xiao W, Xiao C, Yu Y, Kang YM, Du XG, Wei XF, Wang B: Protective immune responses against foot-and-mouth disease virus by vaccination with a DNA vaccine expressing virus-like particles. Viral Immunol 2007 20:429-440.
59. McCullough KC, De Simone F, Brocchi E, Capucci L, Crowther JR, Kinm U: Protective immune response against foot-and-mouth disease. J Virol 1992, 66:1835-1840.

60. O'Shea JJ, Nutman TB: Immunoregulation. In elS. John Wiley \& Sons, Ltd; 2001.

61. Zhang ZD, Hutching G, Kitching P, Alexandersen S: The effects of gamma interferon on replication of foot-and-mouth disease virus in persistently infected bovine cells. Arch Virol 2002, 147:2157-2167.

doi:10.1186/1297-9716-44-48

Cite this article as: Guo et al:: Foot-and-mouth disease virus-like particles produced by a SUMO fusion protein system in Escherichia coli induce potent protective immune responses in guinea pigs, swine and cattle. Veterinary Research 2013 44:48.

\section{Submit your next manuscript to BioMed Central and take full advantage of:}

- Convenient online submission

- Thorough peer review

- No space constraints or color figure charges

- Immediate publication on acceptance

- Inclusion in PubMed, CAS, Scopus and Google Scholar

- Research which is freely available for redistribution

Submit your manuscript at www.biomedcentral.com/submit
C) Biomed Central 